\title{
O cenário nosológico de Goiás no século XIX*
}

\author{
The nosológico scene \\ of Goiás in century XIX
}

\author{
SôNIA MARIA DE MAGALHÃES \\ Doutora em História pela UNESP-Franca \\ R. Major Claudiano, n. 1.488 - CEP 14400-690 - Franca - SP \\ soniademagalhaes@yahoo.com.br
}

RESUMO A província de Goiás gozava de uma situação sanitária ambígua, descrita simultaneamente como saudável e insalubre. Assim, este artigo apresenta diferentes versões sobre as condições nosológicas de Goiás, produzidas pelas autoridades locais, médicos, viajantes estrangeiros e expedições científicas.

Palavras-chave Goiás, saúde, doença

ABSTRACT The province of Goiás enjoyed of ambiguous, described a situation sanitary as healthful and simultaneously unhealthy. Thus, this article presents different versions on the nosológicas conditions of Goiás, produced for the local, medical authorities, travelling foreigners and scientific expeditions.

Key words Goiás, health, disease

Artigo recebido em 17/02/2005; Aprovado em 24/04/2005. 
As péssimas condições sanitárias da província goiana foram bastante apregoadas pelos administradores, viajantes e médicos ao longo do século XIX. No ano de 1860, por exemplo, a Secretaria do Governo Provincial sofreu um grande desfalque no seu quadro de empregados em conseqüência de moléstias, fato que causou atrasos nos registros administrativos. ${ }^{1}$ No ano de 1863, o presidente da divisão administrativa Couto de Magalhães afirmou que a região era doente e lá, não se podia encontrar um só homem saudável: "a mielite, a hidropisia, a hipertrofia do coração, os aneurismas, a lepra de três espécies diferentes, a tísica, as pneumonias, as febres paludosas, o raquitismo e o idiotismo, o bócio, a sífilis, e, sobretudo, as inflamações crônicas do estômago, fígado e intestino" enfraqueciam ou dizimavam boa parte daquela gente. ${ }^{2}$ A mesma impressão teve o presidente Aristides de Souza Spinola, recém-chegado à capital no ano de 1879: "Desde que cheguei a esta cidade incitou-me a curiosidade o grande número de pessoas atacadas de raquitismo, de idiotismo e de bócio que aqui existem. Cumpre averiguar as causas desses males". 3

Os administradores, contudo, já cogitavam que a alimentação deficiente, as precárias condições de vida e a topografia desfavorável da capital - assentada numa profunda bacia de terreno úmido, cercada de montanhas e sujeita a altas temperaturas - talvez explicassem a diversidade de achaques reinantes naquele local. ${ }^{4}$ A província de Goiás gozava de uma situação sanitária ambígua, descrita simultaneamente como saudável e insalubre. Averiguando essa questão, Mary Karasch observa que as diversidades dos ambientes entre o norte e o sul do território contribuíram para classificações duvidosas. As localidades mais deletérias da parte setentrional situavam-se ao longo dos rios Maranhão, Paranã e Bezerra e do sul, nas extensões do Araguaia e do Paranaíba. Mesmo o rio Vermelho, em cujas margens se localizava a capital, possuía péssima fama. As pessoas mais saudáveis e isentas de febres habitavam os planaltos e as montanhas, segundo a opinião dos visitantes. Fica patente, por meio da documentação, que por causa da grande incidência de febres letais, o norte era o pior lugar para se viver (ver mapa 1).

1 Aditamento ao relatório com o que o Exmo. Sr. Dr. Antônio Manoel de Aragão e Mello fez entrega da administração da província de Goiás, o excelentíssimo Sr. Dr. Francisco Januário da Gama Cerqueira. Rio de Janeiro, 1861.Memórias Goianas, no8, 1997, p.118.

2 MAGALHÃES, 1975, p.167.

3 Relatório apresentado à Assembléia Legislativa provincial de Goiás, pelo Exmo. Sr. Dr. Aristides de Souza Spínola, Presidente da província de Goiás, no dia 10 de junho de 1879. Memórias Goianas no12, 1999, p.244.

4 Relatório que o Exmo, Sr. Vice-Presidente da província de Goiás João Bonifácio Gomes de Siqueira entregou à presidência da mesma ao Exmo. Sr. Dr. Francisco Januário da Gama Cerqueira. Memórias Goianas, no7, 1997, p.231. 


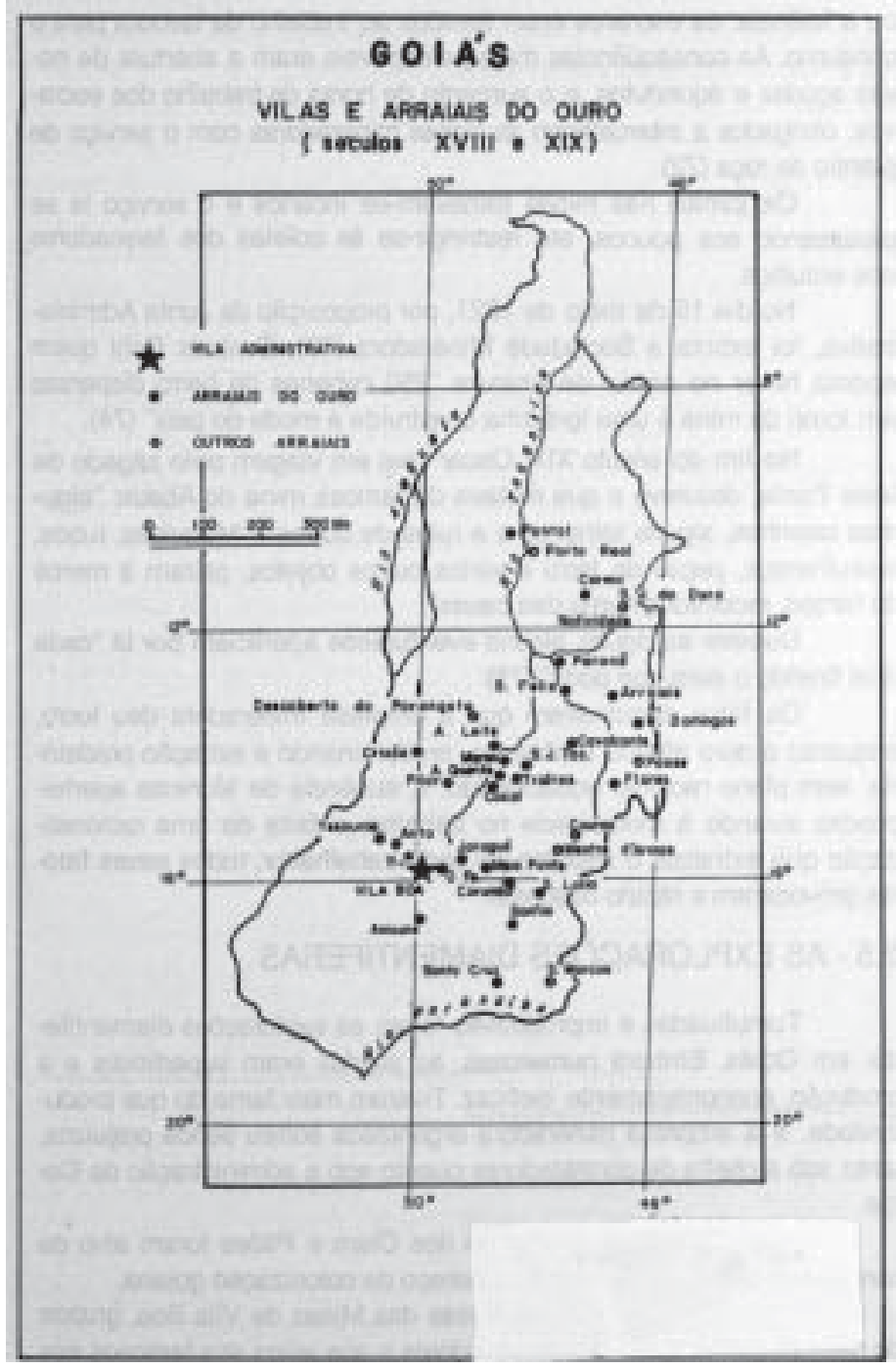

Mapa 1 - Vilas e arraiais do ouro de Goiás, séculos XVIII-XIX.

Transcrito de: SALLES, Gilka V. F. Economia e escravidão na capitania de Goiás. Goiânia: Cegraf/UFG, 1992.

Até o final do século XIX, no campo da medicina, dominava a teoria miasmática, princípio segundo o qual surtos epidêmicos de doenças infecciosas seriam causados pelo ambiente. As condições sanitárias geravam um estado atmosférico, que vinha a causar doenças. ${ }^{5}$ Assim, criouse certa mentalidade preventiva que orientou as ações públicas a partir

5 ROSEN, 1994, p.211. 
da observação de que certos tipos de enfermidades ocorriam com mais freqüência, e várias epidemias e males contagiosos surgiam como conseqüência da falta de higiene, da deficiência alimentar, do saneamento precário ou inexistente, e até mesmo em decorrência de certas condições climáticas locais. Assim, os higienistas se esforçaram desde logo em definir imperativos cuja prática garantia a salubridade do ambiente.

À medida que se adentrava no oitocentos, os administradores e os médicos locais passavam a responsabilizar a localização e a arquitetura da cidade de Goiás como fatores preponderantes para as diversas patologias reinantes.

O antigo arraial de Sant'Anna, fundado em 1726, surgiu como resultado das descobertas auríferas realizadas pelas bandeiras paulistas. Elevou-se à categoria de vila doze anos depois da sua edificação, época em que já abrigava uma imensa população e uma intensa vida comercial, recebendo a denominação de Vila Boa de Goiás. A emancipação à categoria de cidade ocorreria somente no ano de 1819. Construída numa espécie de funil, inteiramente rodeada de morros, possuía um formato alongado e praticamente cortada ao meio pelo rio Vermelho. As ruas largas e retas tinham inadequada pavimentação apesar de calçadas. ${ }^{6}$ Coberta de becos e travessas desiguais, repleta de casas térreas, feitas de taipa, simples e com frontispícios irregulares. ${ }^{7}$ De uma forma geral, predominava o mesmo traçado assimétrico presente em outras localidades originadas á época da mineração do ouro, ignorando-se qualquer norma ou orientação espacial.

Somente com a Lei das atribuições das câmaras de 1828 e as Posturas Municipais de Goiás de 1830 que os administradores procuraram organizar o confuso espaço urbano da capital por meio de medidas preventivas que viessem torná-la mais saudável, tais como arborização das praças, canalização das águas dos chafarizes, proibição de circulação de porcos, cabras e outros animais que pastavam livremente pelas ruas "como se tratasse de uma fazenda de criar...", cujas "manjedouras são colocadas nas próprias casas ou contíguas a estas, o leite muitas vezes é mugido na sala de jantar". ${ }^{8}$ Intensificaram, também, a intolerância aos alienados, aos morféticos e aos portadores de moléstias contagiosas, segmentos considerados perigosos à salubridade do lugar.

Nesse contexto, foram adquiridos imóveis para o estabelecimento do Hospital de Caridade São Pedro de Alcântara9 e do novo mercado municipal. Obras de porte também foram realizadas como a construção do cemitério e do matadouro público. Grandes projetos propondo medi-

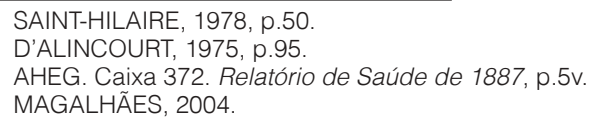


das para tornar a sede da província higienizada também estavam na pauta do dia, inclusive aqueles sugeridos pelos médicos Francisco de Azeredo e José Netto de Campos Carneiro. Azeredo recomendou a remoção do lixo existente em vários lugares, a limpeza das sarjetas da praça do chafariz e do açougue, a desobstrução dos bueiros e a inspeção rigorosa dos gêneros alimentícios vendidos no mercado, medidas prioritárias que dependiam de uma atuação mais enérgica por parte da Câmara Municipal. Interferências maiores, de competência do governo provincial, também se faziam necessárias, como a destruição de alguns prédios visando à facilitação da circulação do ar, a construção do cais da Lapa e a mudança do curso do rio Uru para uma das cabeceiras do rio Vermelho. ${ }^{10} \mathrm{O}$ Inspetor de Saúde, José Netto Carneiro, formado pela Faculdade de Medicina da Bahia ${ }^{11}$, delineou nove pontos para melhorar o estado sanitário da cidade de Goiás: $1^{\circ}$ ) remoção do cemitério para fora da cidade; $2^{\circ}$ ) canalização da água para o abastecimento público; $3^{\circ}$ ) proibição da circulação de animais dentro da cidade; $4^{\circ}$ ) estabelecimento de redes de esgotos nas casas e nas ruas desembocando em um coletor até o rio Vermelho; $5^{\circ}$ ) remoção da enfermaria militar e do hospital São Pedro de Alcântara para fora da cidade; 6) limpeza do córrego Manoel Gomes; 7) drenagem e limpeza do Largo Municipal; $8^{\circ}$ ) maior rigor por parte da Câmara Municipal no cumprimento de suas posturas referentes a higiene pública; 9) maior rigor na limpeza dos edifícios públicos. $^{12}$

A necessidade de sanear a capital tornou-se extremamente urgente no ano de 1890, quando as febres de "mau caráter" e a influenza fizeram inúmeras vítimas na cidade de Goiás e em outros municípios. Essas moléstias chegaram a ceifar diariamente até oito vidas, mortalidade alta para uma pequena localidade que abrigava por volta de dez mil habitantes. ${ }^{13}$ Esse número, aparentemente inexpressivo, era assustador: "algo como se, entre os 600 mil habitantes do Rio de Janeiro de então, ocorressem 480 falecimentos a cada 24 horas". ${ }^{14}$

Desde a segunda metade do século XIX, os médicos, particularmente, inseridos na categoria dos profissionais liberais, encontraram nas cidades o espaço propício para aplicarem seus conhecimentos e sua atuação. Como um dos segmentos da intelectualidade, empenhavam-se na tarefa de ordenar aquilo que era visto como desordem, transformando a cidade num espaço civilizado. ${ }^{15}$ Assim, o médico ampliava, gradativa-

10 Relatório apresentado à Assembléia Legislativa Provincial de Goiás pelo Exmo Sr. Dr. Aristides de Souza Spinola, presidente da província, em 10 de março de 1880. Memórias Goianas, 13, 2001, p.28.

11 BLAKE, 1970, p.106.

12 AHEG. Caixa 372. Ano 1887, p.5v.

13 Mensagem dirigida à Câmara Legislativa de Goiás pelo Governador do Estado Major Dr. Rodolpho Gustavo da Paixão no dia 5/12/1891. Memórias Goianas no15.

14 TEIXEIRA, 1973, p.5.

15 ENGEL, 1989, p.97; p.109-10. 
mente, sua representação, alcançando até mesmo a esfera familiar. Tal difusão inseria-se num projeto maior do Estado, visando consolidar e estender seu desempenho em todas as esferas do social. Por meio de leis impositivas, o governo objetivava moldar profundamente o indivíduo segundo modelos sociais de comportamento, tornando-o produtivo e integrado.

Esse novo sistema de governo caracterizava-se pela proliferação das tecnologias políticas investidas sobre o corpo, a saúde, a forma de se alimentar e de morar, as condições de vida, o espaço completo da existência nos países europeus, a partir do século XVIII. Técnicas que, no seu ponto de partida, encontram seu pólo de unificação naquilo que então se chamava polícia (segundo uma acepção mais ampla, englobando todos os métodos de desenvolvimento da qualidade da população e da potência da nação). A ciência da polícia consistia em regular todas as coisas relativas aos estado presente da sociedade, em consolidá-la, melhorá-la e em agir de forma que tudo concorresse para a felicidade dos membros que a constituíam. ${ }^{16}$

\section{O diagnóstico da comissão exploradora do planalto central do brasil e da expedição científica de Belisário Penna e Artur Neiva}

As mazelas das populações interioranas, em decorrência das precárias situações sanitárias e alimentares, começaram a ser propaladas pelo relatório da Comissão Exploradora do Planalto Central do Brasil. ${ }^{17}$ Contudo, somente a longa expedição de Belisário Pena e Artur Neiva ${ }^{18}$ em 1912, pelo norte da Bahia, sudoeste de Pernambuco, sul do Pará e norte e sul de Goiás, denunciou que os males dos sertanejos resultavam da falta de assistência por parte dos governos.

No período de 1892 a 1893, a Comissão Exploradora do Planalto Central, chefiada por Luís Cruls, elaborou um amplo projeto sobre a geografia física e geológica, a fauna, a flora, a patologia e, especialmente, a climatologia, considerando ainda as facilidades de comunicações para o desenvolvimento dessa área com as outras regiões. Antônio Martins de Azevedo Pimentel, médico higienista dessa comissão, vislumbrou o Brasil Central como "um verdadeiro paraíso", "em que tudo é belo, agradável", ${ }^{19}$ mesmo povoado por pessoas acometidas por uma infinidade

16 FOUCAULT, 1985; DONZELOT, 1986.

17 Em 1892, por determinação do então presidente Floriano Peixoto, uma missão técnico-científica chefiada pelo astrônomo e geógrafo belga Luiz Cruls partiu do Rio de Janeiro com destino ao Planalto Central. Seguindo as determinações presentes na Constituição de 1891, tinha como objetivo demarcar o quadrilátero onde seria constituída a nova capital do país. A missão, que durou de maio a novembro daquele ano, elaborou uma análise cuidadosa da flora, fauna, rios, solos, clima e do modo de vida dos habitantes do Planalto. Ver mais informações em: CRULS, 1947.

18 NEIVA; PENNA, 1984.

19 GEPEL Revista A Informação Goiana, 15/04/1918; 06/1922. 
de moléstias, tais como sífilis, bócio, afecções gastrintestinais crônicas e de alterações do sistema nervoso, malária, pneumonias, broncopneumonias, morféia, epilepsia, histeria, entre outras. Na opinião de Pimentel "nenhuma afecção constante da estatística por mim organizada, e que se acha no meu relatório de 1893, é peculiar à parte explorada do estado de Goiás, nem tão pouco depende do clima". ${ }^{20}$ Atribuía o grande abuso dos condimentos pela alta incidência de doenças gastrintestinais, as bebidas alcoólicas pela degeneração do gênero humano, a ausência de conforto e falta de noções elementares de higiene concorriam para o aparecimento das enfermidades.

Ocultado pela retórica romântica que exaltava as condições pródigas de vida no interior, havia o projeto político de demarcar a área para a nova capital do Brasil estipulada pela Constituição de 1891.

A expedição de Penna e Neiva, organizada pelo Instituto Oswaldo Cruz, ao percorrer durante sete meses o trajeto de mais de quatro mil quilômetros no lombo de cavalo uma extensa área onde predominavam regiões periodicamente amofinadas pela seca, com objetivo de elaborar um levantamento preliminar para a construção de açudes pelo Governo Federal, visitou áreas pouco conhecidas, como certas extensões entre Goiás e Piauí, praticamente privadas de registros feitos por naturalistas estrangeiros ou brasileiros. ${ }^{21} \mathrm{Um}$ argumento peculiar presente no relatório dessa comissão é que, apesar de abandonados e esquecidos, e mesmo vitimados por inúmeras doenças, alguns sertanejos de certas localidades da Bahia e Pernambuco apresentavam-se robustos e resistentes. O cenário patológico, no entanto, mostrava-se aterrorizante, sendo alarmante o número de portadores do mal de Chagas (tripanossomíase americana), especialmente em Goiás. O documento ressalta também os efeitos da fome crônica, denotando "o que figura no obituário como causa mortis é um nome qualquer de moléstia, mas a causa verdadeira, na maioria dos casos, é a fraca resistência do doente que durante a vida passou o martírio da fome parcial", 22 ingerindo alimentos contaminados ou insuficientes para manter o equilíbrio orgânico.

A grande mudança analítica presente na análise de Penna e Neiva quando comparada com a da Comissão Cruls, embora esboce muitas vezes uma imagem negativa da população, está na atribuição de responsabilidade ao governo pela apatia e pelo atraso do brasileiro. A sua improdutividade passava a ser justificada pela doença, decorrente do abandono das autoridades públicas. Imputava-se ao governo, e não mais à natureza, à raça ou ao próprio indivíduo, a responsabilidade pela indi-

20 PIMENTEL, 1907, p.332.

21 HOCHMAN, 1998, p.66.

22 PENNA, 1918, p.53. 
gência de tanta gente que padecia sem assistência e com ausência absoluta de qualquer identificação com o país. Para esses sanitaristas, somente a medicina, aliada ao poder público, seria capaz de transformar "os estranhos habitantes do Brasil em brasileiros". 23

Após divulgar o diagnóstico do Brasil associado a um grande sertão e a um vasto hospital e reivindicar políticas de saneamento para recuperar e integrar o país, a Liga Pró Saneamento, encampada por Belisário Penna, passou a contar com o apoio de vários intelectuais, entre eles, Monteiro Lobato. Da reunião de vários artigos publicados em $O$ Estado de São Paulo, Lobato publicou o livro Problema Vital, ${ }^{24}$ editado pela Liga Pró-Saneamento e pela Sociedade de Eugenia de São Paulo. Nessa obra, Lobato denuncia as endemias do homem da roça que vivia "escravizado" pelos vermes, pela sífilis, pela doença de Chagas e diversas outras.

Os intelectuais agregados à revista A Informação Goiana, principal meio de divulgação das possibilidades econômicas do Brasil Central, entretanto, contestaram as informações do relatório de Neiva e Penna propaladas pelo Correio da Manhã em dezembro de 1916, cuja matéria afirmava que "estaríamos em maus lençóis se a capital do Brasil viesse um dia a ser localizada na área do planalto central, conforme deliberaram os legisladores constituintes". ${ }^{25}$ Em repúdio ao parecer desse relatório, os editores da referida revista, Henrique Silva e Americano do Brasil, endereçaram àquele matutino algumas cartas questionando a veracidade da pesquisa, denunciando "que nenhum médico de Manguinhos fizera pesquisa na área de 14.400 quilômetros quadrados demarcada pela Comissão Cruls para o futuro Distrito Federal da República", cujo médico responsável, o doutor Pimentel, não encontrou na área de Planaltina, sede da nova capital, nenhum caso de impaludismo, leishmaniose (ferida brava ou úlcera de Bauru), doença de Chagas ou outra enfermidade perigosa. ${ }^{26}$

O relatório médico do Instituto Oswaldo Cruz colocou em destaque as mazelas sociais e o abandono dos habitantes do interior do Brasil, uma imagem negativa contrária àquela apregoada pela $A$ Informação Goiana, que proclamava as virtudes de Goiás: "salubérrimo clima, gente saudável, riquezas extraordinárias e suas fontes de vida". ${ }^{27}$ Ademais, os intelectuais goianos acreditavam que, com a edificação da nova capital, Goiás encontraria, enfim, o caminho do seu desenvolvimento econômico e o seu merecido lugar entre os estados mais importantes da federação.

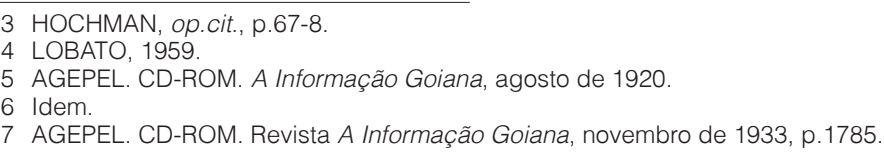




\section{Doenças observadas pelos viajantes estrangeiros}

Os relatos dos viajantes estrangeiros, enquanto manancial de informações, permitem copiosas interpretações. Estudando a biografia desses personagens, Ilka Leite expôs algumas similaridades entre eles, revelando um perfil genericamente denominado "explorador': de novos conhecimentos, de riquezas materiais, de experiências". ${ }^{28}$ As observações desses exploradores, parafraseando Leite, preenchem lacunas e ilustram o cotidiano goiano oitocentista, em especial sobre as doenças, diante do silêncio persistente em outras fontes.

As impressões de Johann Emanuel Pohl, de Saint-Hilaire, Luiz D'Alincourt, de George Gardner e de Francis Castelnau são primordiais para a análise das patologias predominantes em Goiás.

O médico austríaco Pohl aportou no Rio de Janeiro em 1817 e prontamente, no ano seguinte, iniciou uma longa viagem pelas províncias de Minas Gerais, Goiás, Mato Grosso e Pará. Em seu diário abundam observações importantes sobre amplas áreas do conhecimento. O naturalista francês Saint-Hilaire chegou ao Brasil em 1816 e percorreu o território de Goiás em 1819. Já, o relato do militar português D'Alincourt, que se transferiu para o Brasil no ano de 1808, versa sobre a extensa jornada que empreendeu em 1818, do Porto de Santos, passando por Goiás, até Cuiabá, também rico em apontamentos geográficos e topográficos. O naturalista escocês George Gardner residiu no Brasil durante cinco anos, de 1838 a 1843, durante este período percorreu as províncias da Bahia, Alagoas, Pernambuco, Ceará, Piauí, Goiás em 1840 e, por último, Minas Gerais. Em 1843, Francis Castelnau, chefe da expedição francesa às regiões centrais da América do Sul, visitou as províncias de Minas Gerais, Goiás e Mato Grosso. Além de estudos geológicos, zoológicos e metereológicos, delineou aspectos sobre os hábitos e os costumes dos brasileiros.

As condições sociais e intelectuais, as atividades profissionais dos viajantes, obviamente, influíram nas suas observações e impressões. Assim, aqueles que possuíam formação médica, ou relacionados às ciências biológicas, tinham maior competência para elaborar um diagnóstico das patologias reinantes. Os doutores Pohl e Weddell, este último da expedição de Castelnau, em especial, revelaram com maior nitidez o quadro clínico, uma vez que tiveram contato direto com os seus pacientes.

O quadro 1 apresenta diversas moléstias identificadas por Pohl, Saint-Hilaire, D’Alincourt, Gardner e Castelnau na Capitania/Província de Goiás.

28 LEITE, 1996. 


\section{Quadro 1 - Principais doenças contraídas pelos habitantes de Goiás, segundo os viajantes estrangeiros do século XIX.}

\begin{tabular}{|c|c|c|}
\hline Viajantes & Local & Doenças \\
\hline Johann Emanuel Pohl & $\begin{array}{l}\text { Mossâmedes } \\
\text { Água Quente } \\
\text { São Félix } \\
\text { São João da Palma } \\
\text { Aldeia Carretão } \\
\text { (arredores) } \\
\text { São Pedro de Alcântara } \\
\text { Arraias } \\
\text { Traíras } \\
\text { Aldeia Cocal Grande }\end{array}$ & $\begin{array}{l}\text { Bócio, apoplexias nervosas, } \\
\text { hidropisia, ataques catarrais, } \\
\text { elefantíase, sífilis, bexigas. } \\
\text { Bócio } \\
\text { Febre pútrida } \\
\text { Febre e sífilis } \\
\text { Febre maligna } \\
\text { Úlceras cancerosas } \\
\text { Sífilis } \\
\text { Febre } \\
\text { Geofagia } \\
\text { Sífilis e oftalmia }\end{array}$ \\
\hline $\begin{array}{l}\text { August de Saint-Hilaire } \\
\text { Luiz D'Alincourt } \\
\text { George Gardner }\end{array}$ & $\begin{array}{l}\text { Jaraguá } \\
\text { Cidade de Goiás } \\
\text { Aldeia de São José } \\
\text { Cidade de Goiás } \\
\text { Natividade }\end{array}$ & $\begin{array}{l}\text { Hidropisia e morféia } \\
\text { Hidropisia do peito e bócio } \\
\text { Doenças venéreas e sarampo } \\
\text { Bócio } \\
\text { Febres intermitentes e } \\
\text { malignas, oftalmia, sífilis e } \\
\text { bócio. }\end{array}$ \\
\hline Francis Castelnau & $\begin{array}{l}\text { Arraias } \\
\\
\text { Catalão } \\
\text { Palmital } \\
\text { Boa Vista } \\
\\
\text { Amaro Leite } \\
\text { Pilar } \\
\text { Conceição }\end{array}$ & $\begin{array}{l}\text { Febres intermitentes, } \\
\text { reumatismo, doenças } \\
\text { inflamatórias, do baço e do } \\
\text { fígado, dispepsia, bócio, } \\
\text { paralisia e resfriado. } \\
\text { Sarcocele } \\
\text { Bócio } \\
\text { Afecções do aparelho } \\
\text { respiratório, elefantíase do } \\
\text { escroto, oftalmia, bócio, } \\
\text { pênfigo e clorose. } \\
\text { Bócio } \\
\text { Febres } \\
\text { Febres }\end{array}$ \\
\hline
\end{tabular}

Fonte: CASTELNAU, 2000; D'ALINCOURT, 1975; GARDNER, 1975; POHL, 1951; SAINT-HILAIRE, 1975.

A multidão de bociados ou "papudos" dispersos por todo o território impressionaram a todos os estrangeiros. Este dado é importante porque somente quando a carência de iodo chega a um nível extremo é que se observa a presença de bócios maiores ou de casos de cretinismo endêmico. Em São João da Palma, brancos e negros sofriam desse mal, que atacava também os animais, cães e gatos em particular, conforme as 
anotações de Pohl, que viu ainda vários pescoços deformados por três bócios, ${ }^{29}$ dificultando a fala dos portadores. ${ }^{30}$ Em Natividade, a papeira afetava a todos e freqüentemente nasciam crianças com ela. ${ }^{31}$ Parece que só os índios estavam livres desse mal, conforme as impressões de Pohl e Saint-Hilaire em relação aos Caiapós.

Embora vivendo em condições próprias para o estabelecimento de carência crônica de iodo, em regiões desprovidas deste elemento, os índios não desenvolveram a endemia bociosa até o início do século XIX. Para Neto, esta peculiaridade seria explicável por uma característica genética ou, eventualmente, por algum elemento nutricional que suplementaria o mineral a essa etnia. Segundo Josué de Castro, o índio amazonense "não lança mão de nenhum recurso para salvar à fome de sal. Quase não o come, ou quando o faz é de um tipo obtido da cinza de certas plantas queimadas, sal que por sua composição química está longe de melhorar a sua deficiência em sódio porque é mais rico em potássio, que tem funções antagônicas à do sódio". ${ }^{32}$ A baixa de sódio e a subida vicariante de potássio no organismo humano provocam fadiga e esgotamento neuromuscular, mais intensamente em regiões de climas tropicais. Até hoje, o povo Mehinaku do Alto Xingu preparam e consomem o sal vegetal, extraído da folha do aguapé. Entretanto, se consumíssemos esta substância nas mesmas proporções que o utilizamos o nosso tempero, teríamos poucas chances de sobreviver, uma vez que é altamente tóxico, com elevado teor de cloreto de potássio. ${ }^{33}$

Parece que num período bastante curto a mestiçagem suprimiu a aparente "imunidade" do índio em relação ao bócio ${ }^{34}$, de acordo com o relato D'Orbigny, da segunda metade do século XIX, a papeira incidia com maior prevalência nos mestiços, seja de negros e índios (cafuzos), seja nos índios e brancos (mamelucos). ${ }^{35}$

Nessa época, a medicina preventiva, apesar das intensas pesquisas e avanços científicos na identificação das doenças e a determinação de suas causas, caminhava vagarosamente, fato que contribuía para inúmeras especulações em torno do assunto. D'Alincourt menciona, que numa tentativa de reduzir a moléstia dos papos na capital, o ex-Governador D. João Manoel de Menezes mandou destruir uma alameda localizada perto do Palácio do Governo e do chafariz, acreditando que as raízes das árvores contaminavam as águas, provocando a moléstia dos papos. ${ }^{36}$ A gente de Natividade, por sua vez, atribuía a ocorrência do

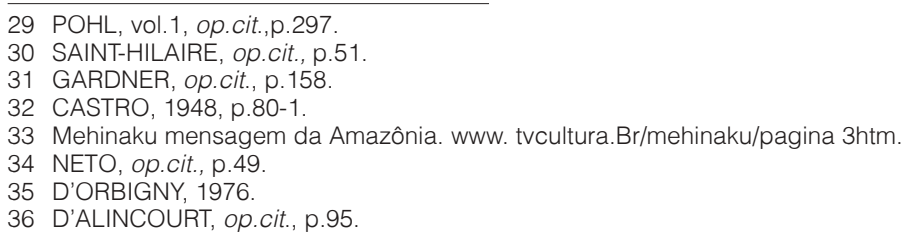


achaque à substituição do "sal da terra", anteriormente mais usado, pelo sal marinho proveniente dos mercados do Pará e à ingestão de água da serra, que aumentava a sua salinidade principalmente na época da seca. ${ }^{37}$ Para Castelnau, a presença do cloreto de magnésio na água conferia a disseminação da papeira em toda a região de Caldas Novas. $^{38}$

Como a etiologia do bócio só seria reconhecida no século XX, empregavam-se vários paliativos, como "massa socada de cupim", "água de cupim" e, topicamente, cataplasmas quentes de abóbora e esponja queimada. ${ }^{39}$ Utilizavam-se desta última os moradores de Natividade, conforme as observações de Gardner. Já em 1819, o escocês Andrew Fype demonstrou que a esponja marinha continha iodo, que deveria ser o elemento ativo na terapêutica. ${ }^{40}$ Pohl, por sua vez, acreditava na ação curativa do ar marinho no combate a essa endemia. ${ }^{41}$ Outro recurso utilizado pelos habitantes de Natividade consistia num "pedacinho de corda que leva à igreja e corta-se exatamente do comprimento do crucifixo para usa-lo em volta do pescoço". Contudo, mesmo depositando grande fé nesse ritual, reconheciam que nenhum efeito causava sobre o edema e nem sequer o impedia de crescer. ${ }^{42}$

Amiúde, as febres agiam intensamente na parte setentrional do território, especialmente ao longo dos rios. O doutor Pohl, que residiu em Goiás por dois anos e teve oportunidade de observar os efeitos do clima sobre a saúde dos habitantes do lugar, delimitou a área insalubre a partir de Água Quente até as cercanias de São João da Palma, onde vigorava a febre pútrida com tal violência que dizimava famílias inteiras e, especialmente, os escravos. ${ }^{43}$ Em Arraias, na época das chuvas, as febres intermitentes levavam muita gente à morte, especialmente aquelas que vinham das terras altas. Ainda que sofressem seus efeitos ao longo da vida, os habitantes das planícies raramente morriam em decorrência dela. ${ }^{44}$ Às vezes, a febre perdia seu caráter intermitente e tornava-se de natureza maligna e renitente, nesse grupo alinhavam-se as tíficas, o "tabardilho" (tifo exantemático), ${ }^{45}$ as disentéricas e outras. ${ }^{46}$

Apesar de manifestar-se mais intensamente no norte, a gente do sul também padecia dos efeitos da malária. A grande incidência na capital

37 GARDNER, op.cit., p.158.

38 CASTELNAU, op.cit.

39 ARAUJO, 1952, p.99.

40 NETO, op.cit., p.9.

41 POHL, op.cit., vol.1, p.297.

42 GARDNER, op.cit., p.159.

43 POHL, op.cit., p.295.

44 GARDNER, op.cit., p.169.

45 doença infectocontagiosa transmitida ao homem pelo piolho, caracterizada por fraqueza, febre alta e erupção maculopapular (mancha).

46 SANTOS FILHO, 1980, p.48. 
devia-se, segundo Saint-Hilaire, à sua localização: "em uma baixada onde a água parece pouco salubre e o calor é quase sempre sufocante durante a seca" pela má saúde da sua população, onde predominavam indivíduos franzinos, sem vigor e energia. Pohl, por sua vez, associou-a ao consumo de água contaminada por folhas em putrefação. ${ }^{47}$

No século XVIII curavam-se as sezões com alho e pinga, ${ }^{48}$ no século seguinte, como poucos podiam comprar sulfato de quinina ${ }^{49}$ para aliviar as febres, apelavam para eméticos, purgantes, cascas amargas e uma forte infusão de café misturado com sal. ${ }^{50}$

A síndrome de hidropisia revelava sintomas de saúde fraca. Ao longo do século XIX deixou de significar apenas acúmulo de líquido nas pernas, ganhando uma conotação mais ampla, sinalizando também problemas cardíacos, renais ou de desnutrição, uma vez que ela acompanhava o beribéri. Especula-se, também, que as manifestações cardíacas que reinavam, sobretudo na capital, ${ }^{51}$ afligindo ainda Meia Ponte e Jaraguá, sugerem a endemicidade da doença de Chagas. As descrições de Gardner reforçam esse indício, pois realçam que em Arraias havia inúmeras pessoas com o baço dilatado, que por vezes crescia a ponto de encher toda a cavidade abdominal. ${ }^{52}$

A sífilis e outras doenças venéreas estavam disseminadas entre brancos, negros, índios e mestiços. Em Traíras, muitos escravos, tão logo souberam da presença do médico Pohl naquelas paragens, recorreram a ele buscando solução para esse mal que os atormentava. ${ }^{53}$ Em São Pedro de Alcântara, esse médico atendeu uma bela mulher que possuía um tumor na coxa de natureza sifilítica. ${ }^{54}$ Os índios tratavam da sífilis com freqüentes lavagens na área afetada. No sul, vangloriava-se muito da eficácia das águas minerais de Caldas Novas e Caldas Velhas, principalmente para reumatismos, moléstias de pele e de origem venérea.

As epidemias de varíola tiveram pouca expressão na província quando comparadas às outras partes do Brasil. Há referências de apenas três surtos significativos: o primeiro em 1771, o segundo no período de 1809 a 1820 e o terceiro de 1873 a $1874 .{ }^{55}$ A baixa incidência pode ser justificada pela prática de inoculação com a vacina de Jenner na Capitania desde 1805, introduzida inclusive nos mais distantes arraiais de Crixás, Pilar, Água Quente, Traíras e São José. Ao longo desse século, apesar da irregularidade, a imunização continuou a ser praticada. Outros

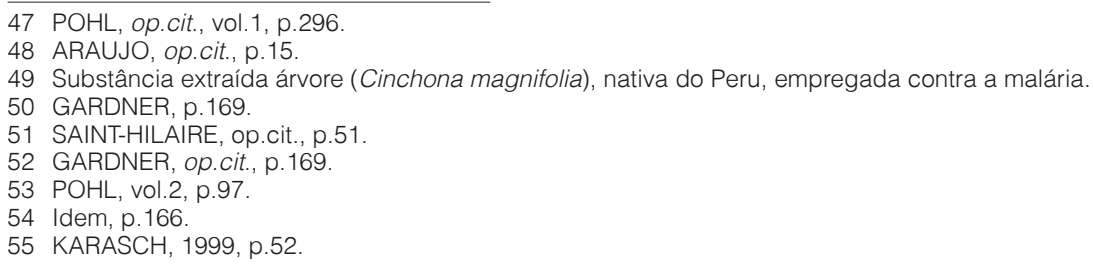


fatores também podem ser considerados, como o isolamento da província, com baixa densidade populacional, e sua característica rural impedia que as pessoas se encontrassem com freqüência, o que diminuía a possibilidade de contágio. Apesar disso, por vezes surgia alguma ocorrência como na distante Aldeia Cocal Grande, onde centenas de índios morreram desfigurados em decorrência de uma epidemia de bexigas. ${ }^{56}$

Castelnau, Gardner e Pohl perceberam as manifestações oculares, como oftalmia e catarata, em Boa Vista, Arraias e na Aldeia Cocal Grande, respectivamente. O primeiro viajante registrou que em nenhum lugar havia encontrado tão grande número de cataratas. ${ }^{57}$ Sobre a notável incidência de problemas oftalmológicos em Goiás, Karasch cogita que podia ter como causas, acidentes, glaucoma não tratado, moléstias contagiosas como lepra, varíola, sarampo e sífilis ou deficiência de vitamina $A^{58}$. Este último fator pode ser sustentado, considerando-se a prevalência da fome e das composições dietéticas banais.

Em suas manifestações mais graves, a carência de vitamina "A" causa alterações oculares (xeroftalmia e querotomalacia) que podem resultar em cegueira por cicatrizes e perfuração da córnea. Durante muito tempo, associou-se a xeroftalmia e a querotomalacia aos retirantes nordestinos, principalmente em épocas de seca. ${ }^{59}$

O doutor Weddell, médico da expedição de Castelnau, ressaltou dois casos de sarcocele ou "elefantíase do escroto", um em Catalão e outro em Boa Vista. Em ambos os casos, o tumor pesava por volta de 20 a 30 quilos e descia até o calcanhar dos portadores, quando de pé. Weddell examinou minuciosamente o enfermo de Boa Vista, que tinha entre trinta e cinco e quarenta anos de idade e convivia com esse tumor, oriundo de uma contusão, havia mais de cinco anos. A uretra e os órgãos anexos conservavam-se sãos. Ademais, o paciente desconhecia outro caso semelhante na sua família. ${ }^{60}$

Entre as doenças que agrediam a pele, destacam-se o pênfigo, a morféia e a elefantíase. Castelnau registrou um caso de pênfigo na localidade de Boa Vista em uma negra que sofria desse mal havia mais de oito anos, cuja pele já estava inteiramente comprometida, "na parte posterior de um dos punhos, apresentava ela diversas vesículas grandes, pelas quais pude sem dificuldade fixar a posição que devia ocupar a moléstia no quadro dermatológico, toda a pele restante era coberta por crostas cinzentas de aspecto mais ou menos foliáceo, fendilhadas e como imbricadas". ${ }^{61}$

56 Idem, p.55

57 POHL, op.cit., p. 155

58 KARASCH, op.cit., p.30

59 SILVA, 1983, p.67.

60 CASTELNAU, op.cit., p.109; 212

61 CASTELNAU, op.cit., p.212. 
O surgimento de bolhas de volume variável compõe sintomas do pênfigo, cujas formas mais conhecidas são a vulgar e a foliácea. Esta última tem uma variedade denominada como "fogo selvagem", que foi inicialmente identificada entre os índios que viviam ao longo do rio Araguaia, em 1902-190362, também encontrada na região Centro-Oeste, em Minas Gerais, Paraná e São Paulo. Afeta principalmente adultos, jovens e crianças que vivem em áreas rurais, próximas a rios e em algumas aldeias indígenas. Caracteriza-se pelo aparecimento de bolhas superficiais que afluem e rompem facilmente, deixando a pele em carne viva, vermelha e recoberta por escamas e crostas. As bolhas começam pela cabeça, pescoço e parte superior do tronco, espalhando-se por todo o corpo. As lesões são dolorosas, com ardência e queimação, daí a designação "fogo selvagem". 63

Os médicos dos séculos XVIII e XIX associavam a elefantíase, a lepra e filariose como morbidades banais entre os escravos provenientes da África. A filariose é causada por parasitas que vivem no sangue ou no tecido subcutâneo, transmitido por picadas de insetos ou através da ingestão de água contaminada. À medida que os parasitas se multiplicam, as pernas, o escroto e os seios incham até alcançarem dimensões abissais. As pernas, em particular, aumentam de volume, tanto a pele quanto o tecido enrijecem, ganhando aspecto elefantino. Nessas condições, o portador, que ficava incapacitado para o trabalho, encontrava na mendicância ou na caridade pública sua única forma de sobrevivência, situação vivenciada por Julião, elefantíaco, casado e com filhos, acolhido no Hospital de Caridade São Pedro de Alcântara, com quatrocentos réis em dinheiro, uma medida de farinha e meia de feijão com o sal correspondente. ${ }^{64} \mathrm{O}$ significativo número de pedintes sofrendo desse mal em Meia Ponte chamou a atenção de Saint-Hilaire: "não se consegue dar um passo no arraial sem esbarrar com mendigos. Vários deles atacados de elefantíase necessitam evidentemente de assistência". ${ }^{65}$

Embora raras no norte da província, as doenças do fígado ou hepatite explicavam-se pelos abusos "no comer e beber e pelo uso constante e imoderado do fumo", segundo a opinião de Gardner. ${ }^{66}$

Nas proximidades de Traíras, Pohl atendeu a uma negra que tinha o ventre terrivelmente inchado em decorrência do costume de comer terra. ${ }^{67}$ Este hábito, muito comum entre os africanos, foi amplamente estudado pelo doutor Wücherer da Faculdade de Medicina da Bahia, que,

\footnotetext{
62 KARASCH, op.cit., p.41.

63 Sobre pênfigo: www.boasaude.com.

64 AHEG. Livro 202. Registro da presidência da província à administração do Hospital São Pedro de Alcântara 1836-1862, p.24v; 26.

65 SAINT- HILAIRE, op.cit., p.38.

66 GARDNER, op.cit., p. 169.

67 POHL, vol.2, p.216.
} 
ao longo das suas pesquisas, recebeu várias designações, "geofagia", "clorose tropical" ou ainda "clorose" oriunda de malária e, posteriormente, simplesmente opilação, doença causada pelo verme ancylostoma duodenale. ${ }^{68}$

Sintomas de neoplasia (tumor) foram identificados por Pohl num índio da Aldeia Carretão, que na época estava com "cerca de quarenta anos, tinha todo coberto de repugnantes úlceras cancerosas, que já havia atingindo também o rosto do infeliz e tinham um aspecto horrivel". Esta descrição, por sua vez, assemelha também a lepra e à morféia, amplamente difundidas naquela província. ${ }^{69}$

Quase todos os Caiapós da Aldeia São José foram vitimados pela epidemia de sarampo anos antes de Saint-Hilaire visitá-los. Só a água fria do rio aliviava o mal-estar e o delírio provocado pela febre. ${ }^{70} \mathrm{Em} 1874$ uma outra pandemia proveniente de Santa Luzia sucumbiu várias crianças. ${ }^{71}$

A documentação de viagem ajuda a localizar e a perceber o ímpeto das enfermidades em Goiás na primeira metade do século XIX, silenciadas, muitas vezes, nos relatórios de presidentes de província e de saúde, bem como nos registros de óbito. Vale lembrar, todavia, que nem sempre os diagnósticos feitos pelos viajantes ou por seus informantes permaneceram e se confirmaram em decorrência da própria circunscrição da medicina.

\section{FONTES}

\section{1- Manuscritas}

AHEG (Arquivo Histórico do Estado de Goiás). Caixa 372. Relatório de Saúde de 1887. AHEG. Livro 202. Registro da presidência da província à administração do Hospital São Pedro de Alcântara 1836-1862.

AHEG. Caixa 235. Pacote 1. Relatório da Delegacia do Serviço sanitário, 1874. AHEG. Caixa 372. Ano 1887.

\section{2 - Impressas}

\section{1-Relatórios}

Memórias Goianas n8. Relatórios políticos, administrativos, econômicos, sociais, etc., dos governos da província de Goiás (1859-1863).Goiânia: UCG, 1997.

Memórias Goianas no12. Relatórios políticos, administrativos, econômicos, sociais, etc., dos governos da província de Goiás (1875-1879).Goiânia: UCG, 1999.

68 Gazeta Médica da Bahia, 15/08/1867, p.32.

69 POHL, op.cit., vol.2, p.128.

70 SAINT-HILAIRE, op. cit., p.69.

71 AHEG. Caixa 235. Pacote 1. Relatório da Delegacia do Serviço sanitário, 1874. 
Memórias Goianas 13. Relatórios políticos, administrativos, econômicos, sociais, etc., dos governos da província de Goiás (1880-1881).Goiânia: SGC, 2001.

Memórias Goianas no15. Relatórios políticos, administrativos, econômicos, sociais, etc., dos governos da província de Goiás (1891-1900). Goiânia: UCG, 2002.

\section{2- Diários de viagens}

D'ALINCOURT, Luiz. Memória sobre a viagem do porto de Santos à cidade de Cuiabá. Belo Horizonte/São Paulo: Itatiaia/Edusp, 1975.

CASTELNAU, Francis. Expedição às regiões centrais da América do Sul. Belo Horizonte/Rio de Janeiro: Itatiaia, 2000.

GARDNER, George. Viagem ao interior do Brasil. Belo Horizonte/São Paulo: Itatiaia/Edusp, 1975.

D'ORBIGNY, Alcides. Viagem pitoresca através do Brasil. Belo Horizonte/ São Paulo: Itatiaia/Edusp, 1976.

POHL, John. E. Viagem no interior do Brasil. 2 vols. Rio de Janeiro: Instituto Nacional do Livro, 1951.

SAINT-HILAIRE, Auguste de. Viagem à província de Goiás. São Paulo/ Belo Horizonte: Edusp/Itatiaia, 1978.

Gazeta Médica da Bahia, 15/08/1867, p.32.

\section{Digitalizadas}

AGEPEL (Agência de Cultura Pedro Ludovico). CD-ROM. A Informação Goiana, agosto de 1920.

AGEPEL. CD-ROM. Revista A Informação Goiana, novembro de 1933.

\section{REFERÊNCIAS BIBLIOGRÁFICAS}

ARAUJO, Carlos da Silva. Matéria médica no Brasil do século XVIII. Rio de Janeiro: Editora A Noite, 1952.

BLAKE, Augusto Vitorino Alves Sacramento. Dicionário bibliográfico brasileiro. Rio de Janeiro: Imprensa Nacional, vol.5, 1970.

CASTRO, Josué de. Geografia da fome. A fome no Brasil. Rio de Janeiro: Empresa Gráfica O Cruzeiro, 1948.

CRULS, Luís. Relatório da Comissão Exploradora do Planalto Central do Brasil. São Paulo: Brasiliense, 1947.

DONZELOT, Jacques. A polícia das famílias. Rio de Janeiro: Graal, 1986.

ENGEL, Magali. Meretrizes e doutores. Saber médico e prostituição no Rio de Janeiro (1840-1890). São Paulo: Brasiliense, 1989.

FOUCAULT, Michel. Microfísica do poder. Rio de Janeiro: Graal, 1985.

HOCHMAN, Gilberto. A era do saneamento. São Paulo: HUCITEC/ANPOCS, 1998.

KARASCH, Mary C. História das doenças e dos cuidados médicos na capitania de Goiás. FREITAS, Lena Castelo Branco Ferreira de. (Org). Saúde e doenças em Goiás. A medicina possivel. Goiânia: UFG, 1999, p.19-62.

LEITE, Ilka B. Antropologia da viagem. Escravos e libertos em Minas Gerais no século XIX. Belo Horizonte: Ed.UFMG, 1996.

LOBATO, José Bento Monteiro. Mr. Slang e o Brasil e problema vital. São Paulo: Brasiliense, 1959.

MAGALHÃES, Couto de. Viagem ao Araguaia. São Paulo, Editora Nacional, 1975. 
MAGALHÃES, Sônia Maria de. Hospital de Caridade São Pedro de Alcântara: assistência e saúde em Goiás ao longo do século XIX. História, Ciência, Saúde Manguinhos, Rio de Janeiro, vol. XI, n`3, p.663-681, 2004.

. Apontamentos históricos sobre a carência alimentar no Brasil. Estudos de História, v.10, n², p.149-164, 2003.

NEIVA, Artur, PENNA, Belisário. Viagem científica pelo norte da Bahia, sudoeste de Pernambuco, sul do Piauí e de norte a sul de Goiás. Brasília: s/e, 1984.

NETO, Geraldo de Medeiros. História do bócio endêmico no Brasil. Origens e causas. São Paulo: Secretaria de Cultura, Esportes e Turismo, 1975.

PENNA, Belisário. Saneamento do Brasil. Rio de Janeiro: Tipografia Revista dos Tribunais, 1918.

PIMENTEL, Martins de Azevedo. O Brasil Central. Revista do Instituto Histórico e Geográfico Brasileiro, tomo 68, parte 1, 1907, p.253-376.

ROSEN, George. Uma história da saúde pública. São Paulo: Hucitec, 1994.

SALLES, Gilka V. F. Economia e escravidão na capitania de Goiás. Goiânia: Cegraf/UFG, 1992.

SANTOS FILHO, Lycurgo. Pequena história da medicina. São Paulo: Parma, 1980.

SILVA, Alberto Carvalho da. Nordeste, desespero ou desesperança. Ciência Hoje, n`5, p.64-70, 1983.

TEIXEIRA, Pedro Ludovico. Memórias. Goiânia: Cultura Goiânia, 1973. 